\title{
Abnormal Facies, Myopia, and Short Stature
}

\author{
C. G. KEITH, R. H. DOBBS, D. G. SHAW, and K. COTTRALL \\ From the Queen Elizabeth Hospital for Children, London
}

Keith, C. G., Dobbs, R. H., Shaw, D. G., and Cottrall, K. (1972). Archives of Disease in Childhood, 47, 787. Abnormal facies, myopia, and short stature. Three members of a family are described who have a curious facies due to a severely depressed nasal bridge, anteverted nostrils, wide-set eyes, high myopia, and short stature. The facial appearance is due to faulty development of the ethmoid bone, which also causes a short anterior cranial fossa. One member of the family was autistic and had a cleft palate. These cases closely resemble, but are thought to be distinct from, a family described by Marshall (1958) whose members had a similar facies which appeared to be due to a defective maxilla, deafness, myopia, and cataracts which were subject to many complications. One further case is described resembling Marshall's cases even more closely; she is deaf but does not have cataracts.

In 1958 Marshall described 7 members of a family who had the following characteristics: the nasal bridge was flattened, the eyes wide set, the nostrils anteverted, the mandible hypoplastic, and the teeth abnormal. Ocularly, there was myopia with a fluid vitreous, congenital and infantile cataracts, spontaneous and sudden maturation and absorption of congenital cataracts, and subluxation of cataracts. The height of the males was about average but the females were short. The intelligence was considered to be slightly subnormal in two patients and the hearing was defective. The skin tended to be soft and dry with little sebaceous secretion and sweating was diminished, which led Marshall to consider that this was a condition akin to ectodermal dysplasia. No further cases seem to have been described since then. In this paper we are reporting three members of a family (Cases 1-3) who have many but not all of the characteristics of Marshall's patients, and one additional case (Case 4) who was diagnosed as Marshall's syndrome at another hospital.

\section{Case Reports}

Case 1. The propositus (Fig. 1 and 2), a male child, delivered by forceps in October 1967 weighing $3.2 \mathrm{~kg}$ was examined at the age of 7 weeks because of a large midline palatal cleft (Fig. 3). His weight was $4 \cdot 16$ $\mathrm{kg}$, height $52 \cdot 7 \mathrm{~cm}$ (10th centile), arm span $39 \cdot 2 \mathrm{~cm}$, lower segment $20.9 \mathrm{~cm}$, and head circumference 39.6 $\mathrm{cm}$. The anterior and posterior fontanelles were very large, with well-marked parietal fontanelles and a

Received 18 February 1972. widely open sagittal suture. The lower jaw was very small, both eyes were protuberant, the nasal bridge

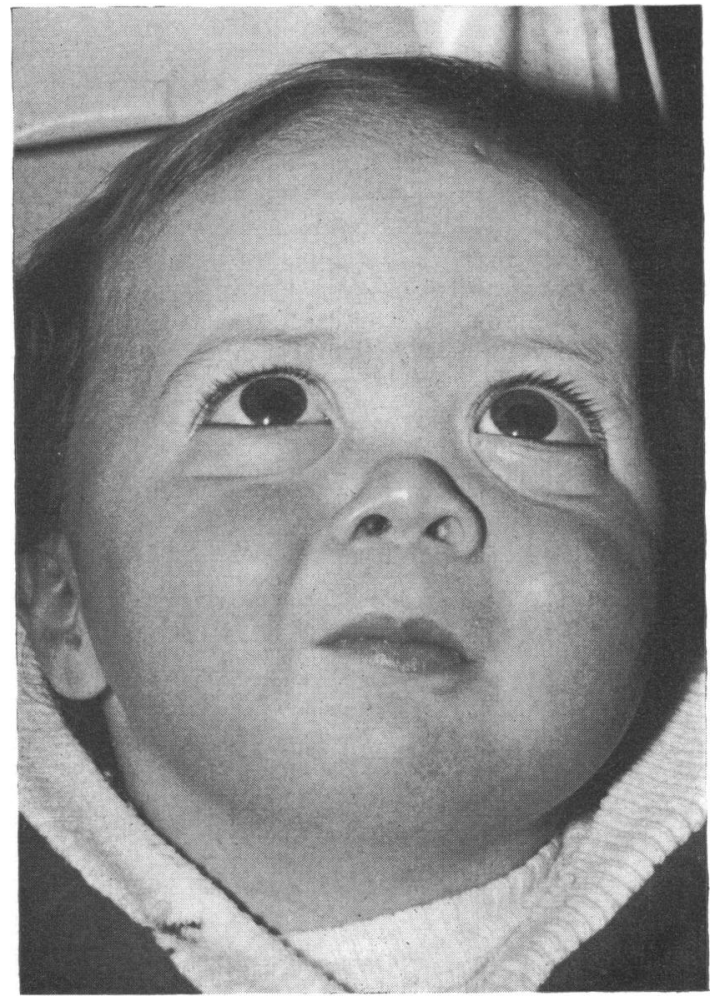

FIG. 1.-Case 1, facies at 27 months, anterior viezv. 


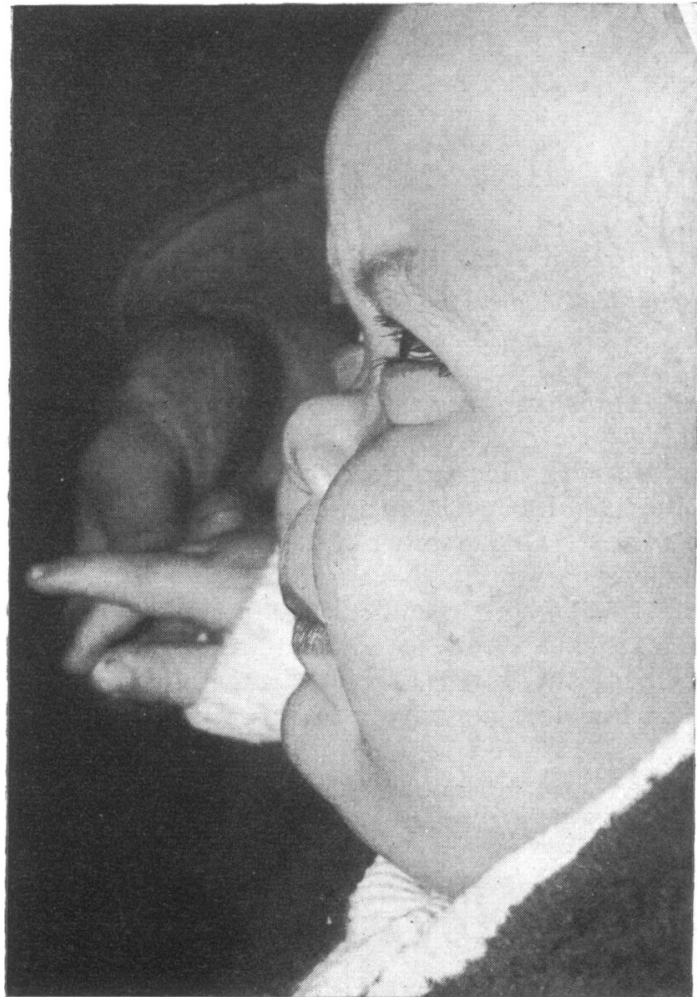

Fig. 2.-Case 1, facies at 27 months, lateral view.

was flat, and the nares pointed forward. The legs and arms were short; the hips showed limitation of abduction and the knees limited extension.

Ocular examination was requested because of the absence of a 'red reflex' in the right eye. The palpebral fissures had a slight antimongoloid slant; the eyes were of normal size, corneal diameters $11.0 \mathrm{~mm}$ approximately; the left fundus was normal, but no view could

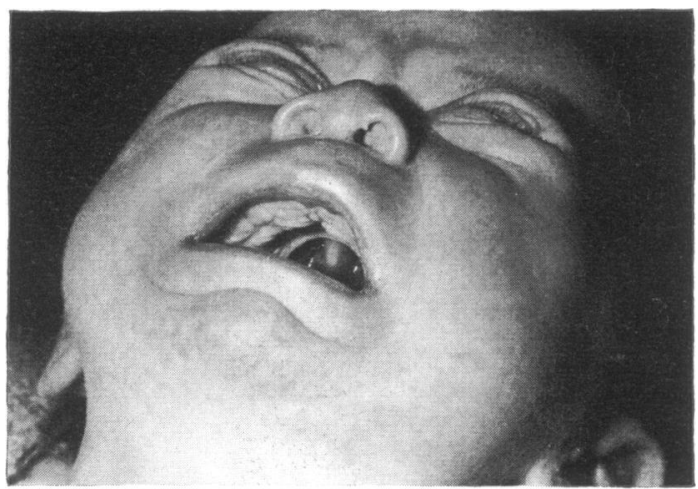

FIG. 3.-Case 1, midline palatal cleft.

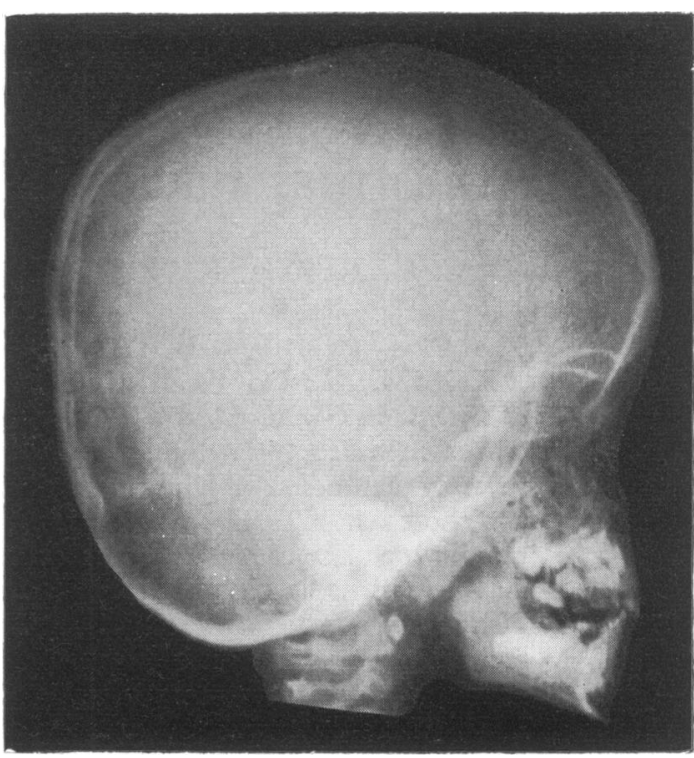

Fig. 4.-Case 1, skull $\mathrm{x}$-ray at 3 years. Lateral view showing brachycephaly, recessed nasal bones, short ethmoid, and short anterior cranial fossa.

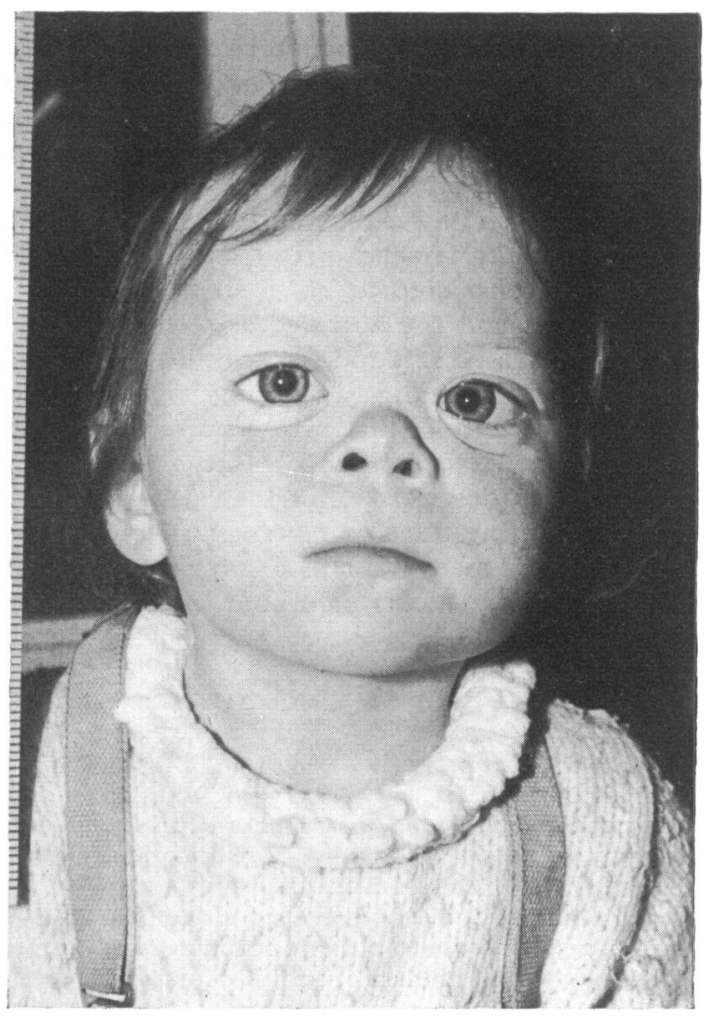

FIG. 5.-Case 2, facies at 18 months, anterior view. 


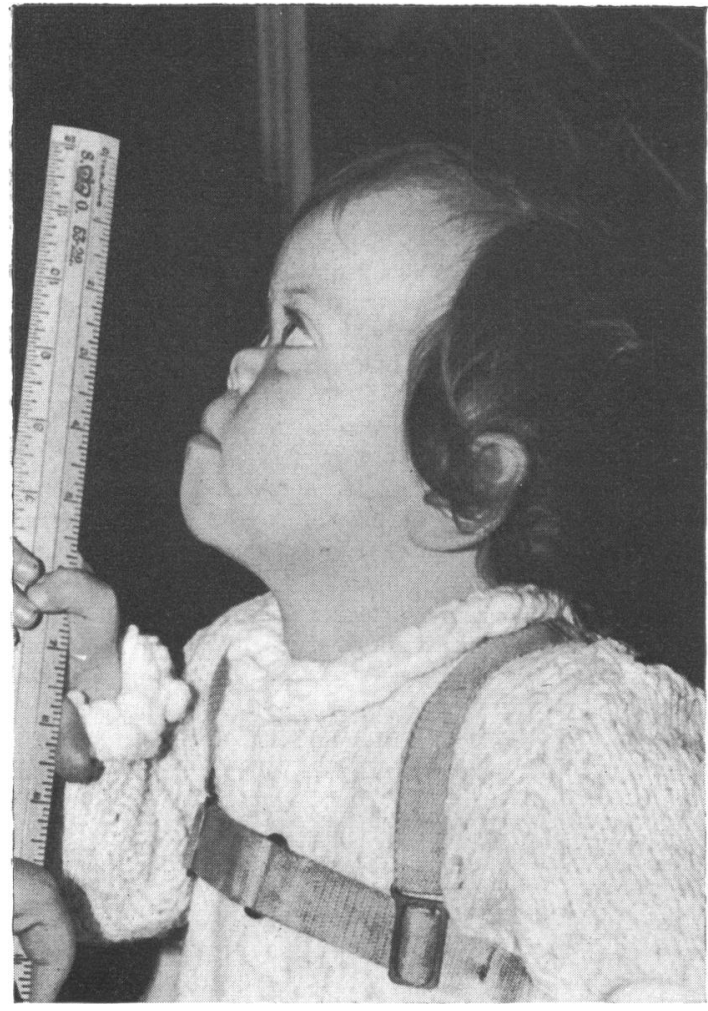

Fig. 6.-Case 2, facies at 18 months, lateral view.

be obtained of the right fundus due to a vitreous haemorrhage. This gradually cleared to reveal a retinal haemorrhage above the macula, which also cleared spontaneously. The refractive error of both eyes was approximately -20.0 DS. At the age of $3 \frac{1}{2}$ years there were still some hyaloid remnants present in both eyes and some capsulohyaloid vessels in the right eye. The fundi were poorly pigmented and there was one patch of myopic atrophy near the left disc, but apart from this they were normal.

A skull $x$-ray taken at 7 weeks showed the ethmoid bone and the anterior cranial fossa to be decreased in length anteroposteriorly; the forehead was bulging, and the nasal bones poorly developed. The maxilla appeared normal but recessed. Further $x$-rays (Fig. 4) taken at 3 years of age showed brachycephaly, with underdevelopment of the ethmoid bone; the nasal bones and maxilla were still recessed. The mandible was small, but the cranial sutures had evolved normally. The long bones of the skeleton were slightly flared and the 'bone age' was under 2 years.

At the age of 3 , his height $(87 \mathrm{~cm})$ and weight $(11 \cdot 7$ $\mathrm{kg}$ ) were both near the 3 rd centile, while his head was comparatively large, OFC $51 \mathrm{~cm}$ and the arm span was $82 \mathrm{~cm}$. His behaviour was very retarded and he was at this time considered autistic; he could only sit unsupported and moved round on his bottom. He spent much of his time rocking backwards and forwards while looking up at the ceiling lights. His hearing was apparently satisfactory but he did not speak or reach out for objects but he did appear to see them; he could hold a feeding bottle himself but would consume no solid food. He was not toilet trained.

Full haematological, serological, biochemical, and cytogenic studies were carried out, but all were normal except for slightly raised levels of free proline, proline peptide, and hydroxyproline in the urine at 7 weeks of age, but later tests were normal. At one stage he developed an iron deficiency anaemia due to his poor diet but it responded well to treatment.

Case 2. The sister of the propositus (Fig. 5 and 6), born in July 1966, was examined at the age of 18 months. She had been noted to be holding things very close in order to see them. Her facies were very similar to her mother and brother (Cases 1 and 3). The eyes were wide set (interpupillary distance $48 \mathrm{~mm}$ ), the bridge of the nose was flattened and the nares pointed forwards, and there were marked inverse epicanthic folds. The eyes were of normal size, the ocular movements were full but an alternating concomitant convergent squint of $25^{\circ}$ was present. The ocular media were

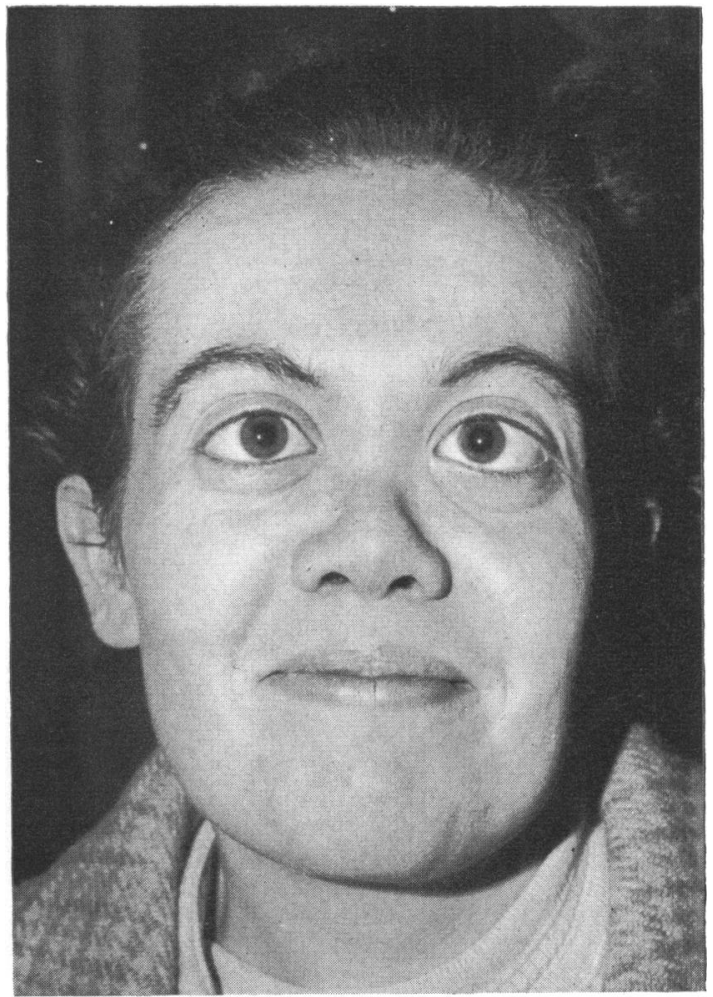

FIG. 7.-Case 3, facies at 31 years, anterior view. 
clear and the fundi appeared albinotic but the optic discs and retinal vessels were normal. Refraction then showed a very high myopia of approximately $-17 \cdot 0$ DS, which progressed, and at the age of 4 years 10 months the prescription was $\mathrm{R}$. $-20 \cdot 0 \mathrm{DS} /-4.0 \mathrm{DC}$ axis $30^{\circ}$. L. $-19.0 \mathrm{DS} /-4.0 \mathrm{DC}$ axis $150^{\circ}$, giving visual acuities of $R$. $6 / 18$ and N8, L. 6/24 and N36. Also at this age her measurements were as follows: height $101 \mathrm{~cm}$, weight $16 \mathrm{~kg}$, both above the 10th centile; arm span $96 \mathrm{~cm}$ and OFC $51 \mathrm{~cm}$. $X$-rays showed that the floor of the anterior cranial fossa was shorter than normal but the rest of the vault appeared normal. The ethmoid bone appeared to be smaller in the anterior posterior dimension than normal, and the nasal bones were consequently recessed. The basal angle was normal. The 'bone age' was about 6 years. Thus this child is short with abnormal facies, she appears to be of above average intelligence and has poor vision due to severe myopia. No metabolic defect has been detected.

Case 3. Mother of Cases 1 and 2 (Fig. 7). (The father is not consanguineous, is of above average height, and does not resemble any of the other members of the family.) She was born of an English father and an
Anglo-Swiss mother. She was found to be myopic at the age of 18 months and had worn glasses since then. She was educated at a school for the partially sighted $S$ and had been told that she would probably be blind when she was an adult. Her refractive error and visual acuity is $\mathrm{R}$. $-22 \cdot 0 \mathrm{DS} /-3.0 \mathrm{DC}$ axis $60^{\circ}=6 / 24$. L. $-22 \cdot 5 \mathrm{DS} /-2 \cdot 0 \mathrm{DC}$ axis $110^{\circ}=6 / 9$.

She has only one sib, a sister, who does not resemble her in facial appearance, nor do any of the other preceding members of the family. Apart from the facies and short stature, her only abnormality is one leg shorter than the other. Her measurements are as follows: height $150 \mathrm{~cm}$, weight $59.5 \mathrm{~kg}$, arm span $147 \mathrm{~cm}$, OFC $96 \mathrm{~cm}$. Her intelligence seems above the average and she has had no serious past illnesses.

$X$-ray of the skull (Fig. 8) showed that the ethmoid bone was decreased in its anteroposterior and lateral dimensions. The nasal bones were recessed as a result of this malformation. The anterior cranial fossa was small in its anteroposterior dimension, with marked overgrowth of the frontal sinus. There was some recession of the upper part of the maxilla but the antra appeared normally developed. The premaxilla and alveolar processes of the maxilla appeared normal. The mandible was within the normal limits and the

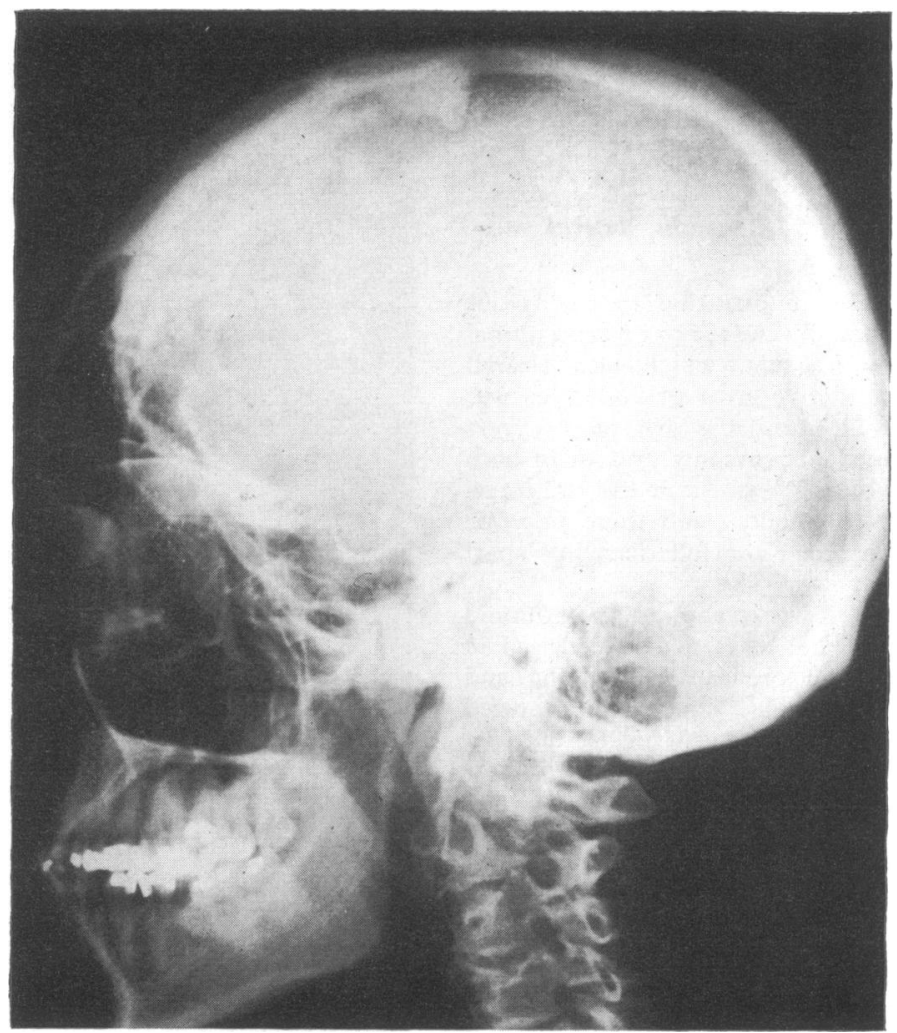

FIG. 8.-Case 3, skull x-ray at 31 years, lateral view showing recessed nasal bones, short ethmoid, short anterior cranial fossa, and large frontal sinus. 


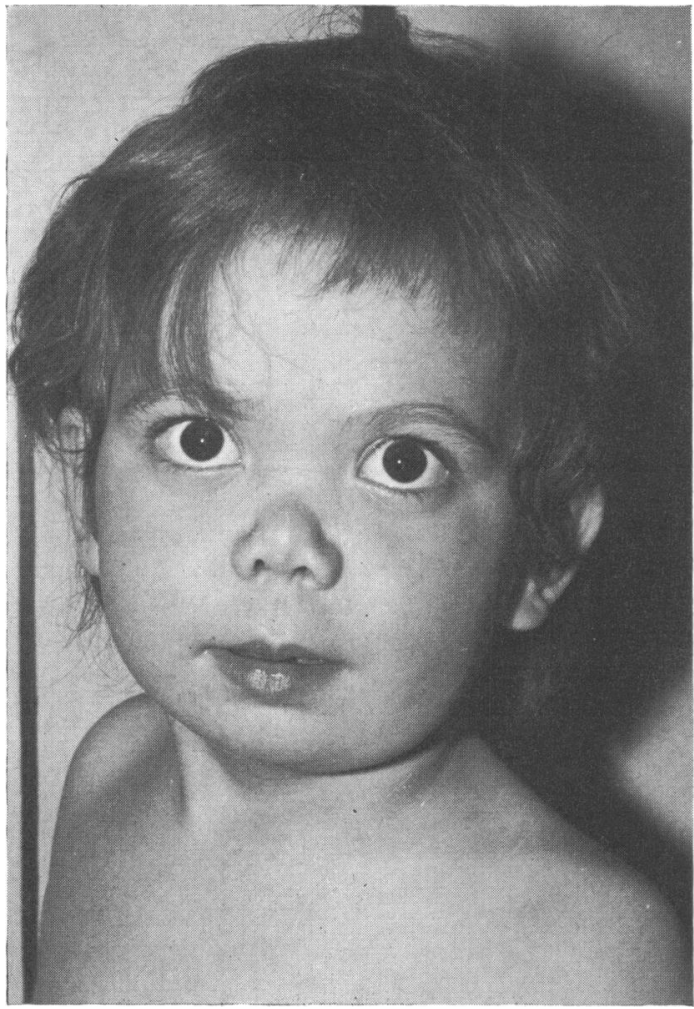

FIG. 9.-Case 4, facies at 4 years 10 months, anterior view.

teeth occluded well. The sphenoid and sella were normal. There was marked hyperostosis frontalis internalis and calcification in the falx cerebri. The sphenoid angle measured $135^{\circ}$ (within normal limits). The teeth were normal.

Case 4. This child (Fig. 9 and 10) was seen to have very similar features to Cases 1 to 3 , but full clinical details are not available because she is under the care of another hospital where the diagnosis of Marshall's syndrome was made. She was born in September 1966 by normal delivery at 41 weeks' gestation, weighing $3.5 \mathrm{~kg}$, the first child of nonconsanguineous parents, and was referred to hospital at the age of 3 months because of poor sight and deafness. The latter was confirmed and the former was found to be due to high myopia. The correction being $R$. $-13 \cdot 0 \mathrm{DS} /-2 \cdot 0$ $\mathrm{DC}$ axis $180^{\circ}$. L. $-14.0 \mathrm{DS} /-2.0 \mathrm{DC}$ axis $180^{\circ}$, both fundi were normal except for myopic crescents, and there were no cataracts.

Since infancy she has been treated for repeated attacks of upper respiratory tract infection and she attends an audiology department for hearing aids. Her speech is retarded and it is considered that her IQ is low, even allowing for her sensory deprivation. She did not sit until 1 year of age, nor walk till $2 \frac{1}{2}$ years. Radiological

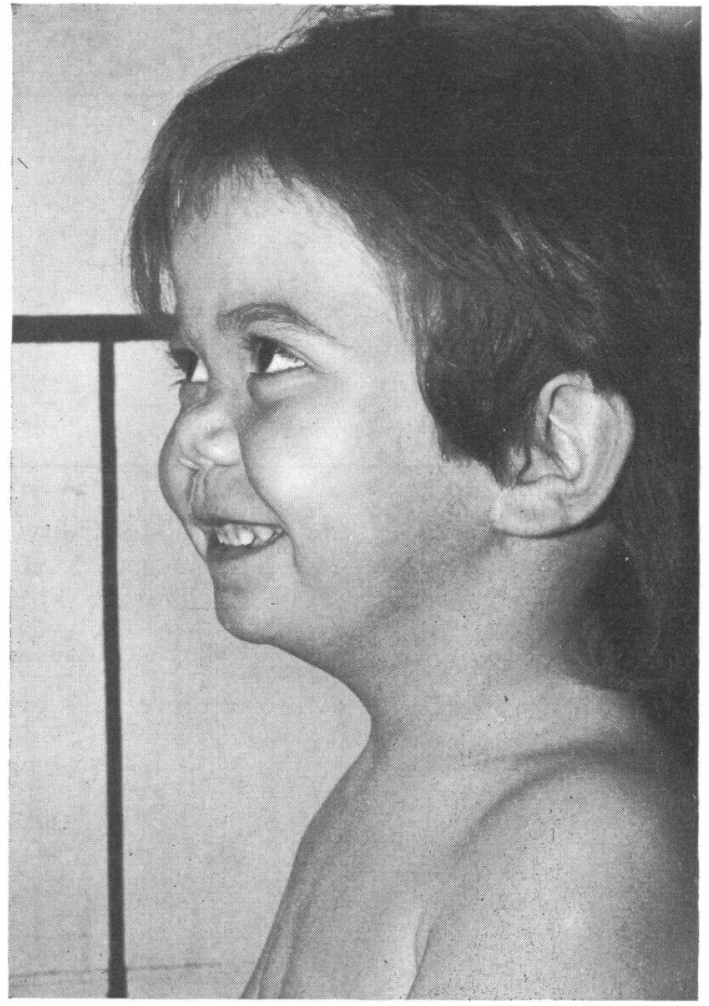

FIG. 10.-Case 4, facies at 4 years 10 months, lateral view.

and haematological investigations carried out over the years were mainly concerned with the current pathological problems; the serum protein levels were normal and there was no aminoaciduria. Her weight fluctuated because of the infections but it was usually above the 25th centile, while her height stayed below the 10th centile. Recent ocular examination showed no cataract or dislocation of the lenses.

Skull $x$-rays showed depressed nasal bones, absent frontal sinuses, normal sized anterior cranial fossa and sella turcica, and normal teeth. The general skeletal development and bone age were not retarded. Tomograms of the inner ear were normal.

\section{Discussion}

The four cases described here share many of the features of the family described by Marshall (1958) (Table), the most obvious similarity being in the curious facies, the appearance of which seems to be mainly due to the depressed nasal bridge and wide set eyes, while the anteverted nostrils are probably secondary to the bridge defect.

Smith (1970) does not consider that depression of the nasal bridge with mildly upturned nares is of 
TABLE

Comparison of Features Found in Marshall's Cases and Those Presented Here

\begin{tabular}{|c|c|c|c|c|c|}
\hline Feature & Case 1 & Case 2 & Case 3 & Case 4 & Marshall's Cases \\
\hline $\begin{array}{l}\text { Depressed nasal bridge } \\
\text { Anteverted nostrils } \\
\text { Wide-set eyes } \\
\text { Myopia } \\
\text { Cataracts } \\
\text { Deafness } \\
\text { Marked shortness of stature } \\
\text { Cleft palate } \\
\text { Defective ethmoid bone } \\
\text { Defective maxilla } \\
\text { Dental abnormalities }\end{array}$ & $\begin{array}{l}+ \\
+ \\
+ \\
+ \\
- \\
+ \\
+ \\
+\end{array}$ & $\begin{array}{l}+ \\
+ \\
+ \\
+ \\
+ \\
+ \\
+\end{array}$ & $\begin{array}{l}+ \\
+ \\
+ \\
+ \\
- \\
+ \\
+ \\
-\end{array}$ & $\begin{array}{l}+ \\
+ \\
+ \\
+ \\
+ \\
+ \\
+ \\
-\end{array}$ & $\begin{array}{l}+ \\
+ \\
+ \\
+ \\
+ \\
+ \\
- \\
+ \\
+\end{array}$ \\
\hline
\end{tabular}

great significance as a developmental abnormality, but in the cases presented here the degree is so marked that we consider it to be significant. The bridge of the nose (Fig. 11) is formed by the nasal bones, supported posterosuperiorly by the nasal process of the frontal bones, posteroinferiorly by the perpendicular plate of the ethmoid, and laterally by the frontal process of the maxillae; flattening can be caused by different factors affecting the various bones involved. Marshall found in the two cases $x$-rayed that the nasal bones were small, short, and set far back from their normal position,

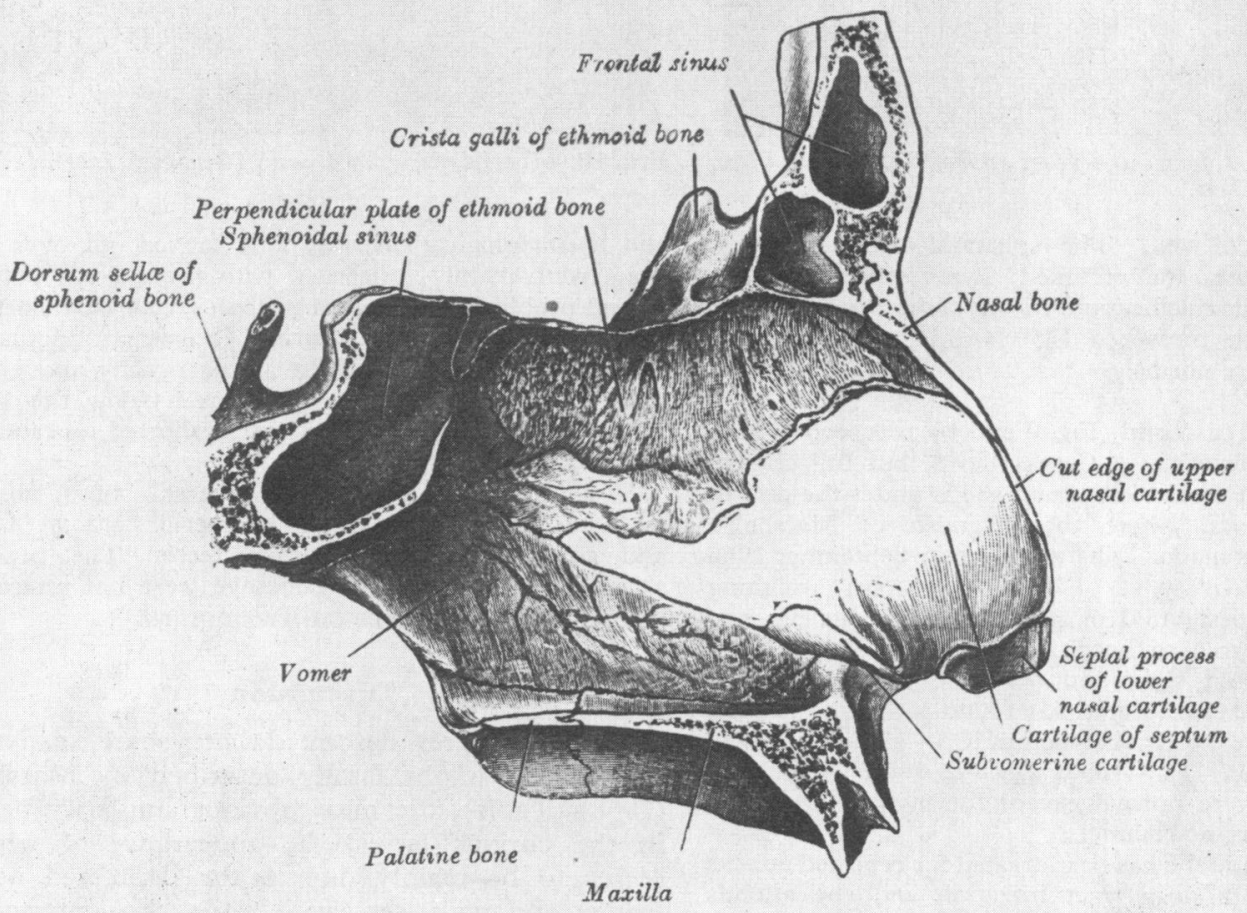

Fig. 11.-Nasal septum. (Reproduced from Gray's Anatomy, 28th ed., 1945, fig. 1009, b. 1169, by permission of $J$. and A. Churchill, London.) 
and the maxilla appeared wedge-shaped with the front part being shorter than the back; he considered that this was responsible for the nasal flattening. In our Cases 1, 2, and 3 the maxilla appeared recessed but normal; however, the ethmoid bone was found to be short in the anteroposterior dimension; this caused not only a flattened nasal bridge but also a short anterior cranial fossa, so the similarity in appearance between these and Marshall's cases may be fortuitous and due to different underlying causes. The $x$-rays of Case 4 showed depression of the nasal bones, but there was no obvious defect in either the maxilla or the ethmoid bone.

The only other feature that all our cases had in common with Marshall's cases was the myopia, generally of much higher degree in our group. Deafness was found only in our Case 4, while it was present in all his cases. The other main points of difference are in the severe ocular complications suffered by all his cases with their cataracts which spontaneously luxated or ruptured, and the surgical difficulties that they posed at operation. Three of his cases were aged 5, 7, and 13, respectively, when they required operation for cataract. Three of our cases are under 7 years of age so they may well develop further complications, but there is no sign of lens opacity at this stage. Case 3, now 31 years, has no ocular abnormality apart from myopia which is in fact following a rather benign course. The height of all our cases is well below the average, while Marshall's male cases were average and the females slightly below average. The intelligence of our Cases 2 and 3 is above average, Case 4 is low, while Case 1 is autistic. Marshall considered the intellect of his cases to be generally average, while two were slightly subnormal.

On the basis of the facial appearances, the mild abnormalities in the skin and teeth and also the cataracts, he thought that his cases represented a type of ectodermal dysplasia, but the evidence for this seems to be rather tenuous, and there does not seem to be any ectodermal dysplastic features in the cases reported here.

It is possible that Marshall's cases and ours form part of a spectrum of a congenital abnormality, but it is more probable that Cases 1 to 3 form a separate entity characterized by the facies which is due to a defect in the ethmoidal bone, a short anterior cranial fossa, high myopia, and short stature, with other defects being present in only one of the group. Case 4 more closely resembles Marshall's cases.

We wish to express our thanks to Dr. Liebeschuetz of Southend General Hospital for allowing us to examine his patient (Case 4).

Marshall, D. (1958). Ectodermal dysplasia: report of a kindred with ocular abnormalities and hearing defect. American fournal of Ophthalmology, 5 (4/2), 143.

Smith, D. W. (1970). Recognizable Patterns of Human Malformation, p. 348 . Saunders, Philadelphia.

Correspondence to Mr. C. G. Keith, F.R.C.S., Queen Elizabeth Hospital for Children, Hackney Road, London E2 8PS. 